\title{
Identification of Loss Factor of Fiber-Reinforced Composite Based on Complex Modulus Method
}

\author{
Hui Li, Yi Niu, Chao Mu, and Bangchun Wen \\ School of Mechanical Engineering and Automation, Northeastern University, No. 3-11 Wenhua Road, Heping District, \\ Shenyang 110819, China \\ Correspondence should be addressed to Hui Li; lh200300206@163.com
}

Received 7 July 2017; Revised 31 August 2017; Accepted 11 September 2017; Published 19 October 2017

Academic Editor: Sergio De Rosa

Copyright (C) 2017 Hui Li et al. This is an open access article distributed under the Creative Commons Attribution License, which permits unrestricted use, distribution, and reproduction in any medium, provided the original work is properly cited.

\begin{abstract}
The identification of the loss factor of fiber-reinforced composite based on complex modulus method is presented. Firstly, the damping model of fiber-reinforced composite plate is established, and the relation between each loss factor and modal damping ratio is deduced based on the complex modulus method. Then, the least square relative error function is formed by using the modal damping ratio obtained in the experimental test, and the appropriate step-size is selected in the range of $0 \sim 10 \%$ to calculate the loss factor. Next, the identification procedure of loss factor of such composite material is summarized, and the corresponding identification procedure is realized based on self-designed MATLAB program. Finally, TC300 carbon/epoxy composite plate is taken as an example to carry out a case study, and its loss factors along the longitudinal, transverse, and shear direction are identified by the complex modulus method. By comparing the measured damping results obtained in this paper and the calculated damping results based on the Adams-Bacon model with the same loss factor, it is found that the corresponding maximum deviation between them is less than $15 \%$, so the correctness of such identification method has been verified indirectly, which can be used to identify loss factor of fiber-reinforced composite with high precision and efficiency.
\end{abstract}

\section{Introduction}

Fiber-reinforced composite has excellent mechanical properties, good thermal stability, and capability for weight reduction, which is widely used in the area of aeronautics, astronautics, automotive, naval vessel, and weapon industry $[1,2]$. Currently, there are a large number of such composite thin walled structures, such as solar panels, aircraft engine fan blades, and large wind turbine blades. Loss factor is a key parameter for such type of composite, which has significant influence on vibration control, noise suppression, and fatigue life of composite structures, and usually it can be divided into longitudinal, transverse, and shear direction due to its anisotropy property. But, because of the complexity of the microstructure and different dynamic loads on the composite structures [3,4], for instance, the loss factor is not only closely related to fiber orientation, fiber/matrix interface conditions, material preparation process, environmental temperature, and and other factors, but also closely related to the external excitation frequency and amplitude $[5,6]$. Therefore, it is of great importance to study the damping property of fiberreinforced composite material and its structure, especially the corresponding damping analysis methods and identification techniques.

At present, great progress has been made in the identification of the loss factor of fiber-reinforced composites. Adams and Bacon [7] firstly established the macroscopic model of fiber-reinforced composite plate, which was called AdamsBacon damping model. They considered that the energy consumed by each thin layer in the composite plate was the sum of its longitudinal tensile, transverse tensile, and shear stresses. Therefore, the damping capacity of the thin layer can be defined as the ratio of the dissipated energy to the stored strain energy. Rao and He [8] presented closed-form solutions for resonance frequencies and modal loss factors of laminated composite beams with multiple viscoelastic layers by the energy formulation and Ritz method. Rikards et al. [9] established the damping model of the composite plate by introducing the complex elastic moduli, and the frequency dependence of the loss factor in the longitudinal, 
transverse, and shear directions of composite plates was studied, but they only obtained bending loss factor at different frequencies and also did not give the detailed identification procedure of loss factors $\eta_{11}, \eta_{22}$, and $\eta_{12}$. De Visscher et al. [10] proposed a mixed numerical-experimental method for the identification of the material damping properties of fiber-reinforced polymer composites, and the complex elastic moduli were introduced, so that the modal strain energy can be expressed as the sum of four partial energies which were longitudinal tensile, transverse tensile, shear stresses, and thickness direction. Dalenbring [11] proposed a threedimensional material damping estimation methodology for planar isotropic material symmetry by using a constitutive viscoelastic vibration model, and an experimental study of the loss factors of the fiber-reinforced composite was carried out. Melo and Radford [12] established an analytical model based on only five independent dynamic stiffness parameters and three independent damping loss factors, and, by using this model, a method was developed based on energy equations. Kostopoulos and Korontzis [13] introduced a mixed analytical-experimental approach for the measurement of the loss factors with frequency dependence of the single lamina, and the effects of experimental errors on the evaluation of the viscoelastic properties of the single lamina were discussed. Chandra et al. [14] measured all the six loss factors for glass fiber-reinforced composite (three in normal and three in shear) by the free decay method in the vacuum chamber, and different types of specimen such as beam, tubular, and cuboidal in shape were tested under different loading conditions. Berthelot and Sefrani [15] presented an extensive analysis of the damping of unidirectional fiber composite as function of frequency and fiber orientation, and the longitudinal loss factor can be identified for $0^{\circ}$ fiber orientation while the transverse loss factor can be identified for $90^{\circ}$ fiber orientation. Berthelot [16] also presented an analysis of the damping of unidirectional fiber composites and different laminates, and damping modeling of unidirectional composites and laminates was developed using the Ritz method for describing the flexural vibrations of beams or plates. Kumar et al. [17] proposed three-phase mathematical model for the evaluation of damping incorporating the effect of fiber packing, and the longitudinal loss factor, transverse loss factor, transverse shear loss factor, and longitudinal shear loss factor were predicted under different interphase volume fractions. Shokrieh and Najafi [18] measured the specific damping capacity and loss factors of laminated polymer matrix composite under the frequency of $0.2 \mathrm{~Hz}-4 \mathrm{~Hz}$, and its viscoelastic behavior was characterized by using a modified classical lamination theory. Matter et al. [19] presented a mixed numerical-experimental identification method for estimating the loss factor of composite plates and shells, and the natural frequencies, modal damping factors, and mode shapes of the specimen were measured with an optimized contact-free experimental setup, which used a loudspeaker for exciting the structure and a scanning laser interferometer for measuring the dynamic response. Devalve and Pitchumani [20] investigated the damping effects of carbon nanotubes embedded in the matrix of fiber-reinforced composite material, and dynamic mechanical analysis (DMA) system was employed in the dual-cantilever mode of the composite beam to measure its material loss factor.

Although many researchers have studied the identification of the loss factor of fiber-reinforced composite plates, most of them usually regard the elasticity modulus as a real number, and few literatures have studied the damping characteristics of composite structures with complex modulus method, which regard the elasticity modulus as an imaginary number. At present, the complex modulus theory has been widely used to describe the damping properties of viscoelastic material and structure [21, 22], and it has a series of advantages, such as simple theoretical principle, high calculation accuracy and low cost of time expenditure. Therefore, in this research, such theory method is extended to identify the loss factor of fiber-reinforced composites, which is a new try to find out the identification solution of damping property of fiber-reinforced composite material.

In this research, the identification of loss factor of fiberreinforced composite based on complex modulus method is presented. Firstly, in Section 2, the damping model of fiberreinforced composite plate is established as an example, and the total strain energy and dissipation energy expressions are deduced, so that the relation between each loss factor and the modal damping ratio can be determined based on the complex modulus method. Besides, the least square relative error function is formed by using the modal damping ratio obtained by experimental test, and the appropriate stepsize is selected in the range of $0 \sim 10 \%$ to calculate the loss factor. Then, in Section 3, the identification procedure of loss factor of such composite laminates is summarized, and the corresponding identification procedure is realized based on self-designed MATLAB program. Finally, in Section 4, by taking the TC300 carbon/epoxy composite plate as the research object, the damping parameters are measured in experiment, and the loss factor is also identified by the complex modulus method. And, by comparing the measured damping results obtained in this paper and the calculated damping results based on the Adams-Bacon model with the same loss factor, the correctness of such identification method has been verified indirectly.

\section{Theoretical Principle of Identifying Loss Factor of Fiber-Reinforced Composite Based on Complex Modulus Method}

In this section, complex modulus method is proposed to identify loss factor of fiber-reinforced composites, which is based on the established damping model of composite thin plate, and its theoretical principle is explained in the following.

2.1. Damping Model of Composite Thin Plate. The fiberreinforced composite thin plate, which is made of fiber and matrix material with orthotropic $s$ layers, is introduced in Figure 1. Firstly, the coordinate system xoy is set up at the middle surface, in which the length, width, and thickness of the composite plate can be expressed as $a, b$, and $h$, while the fiber direction within a layer is defined as $\theta$ from the $x$-axis of coordinate system xoy. Besides, each layer of the 


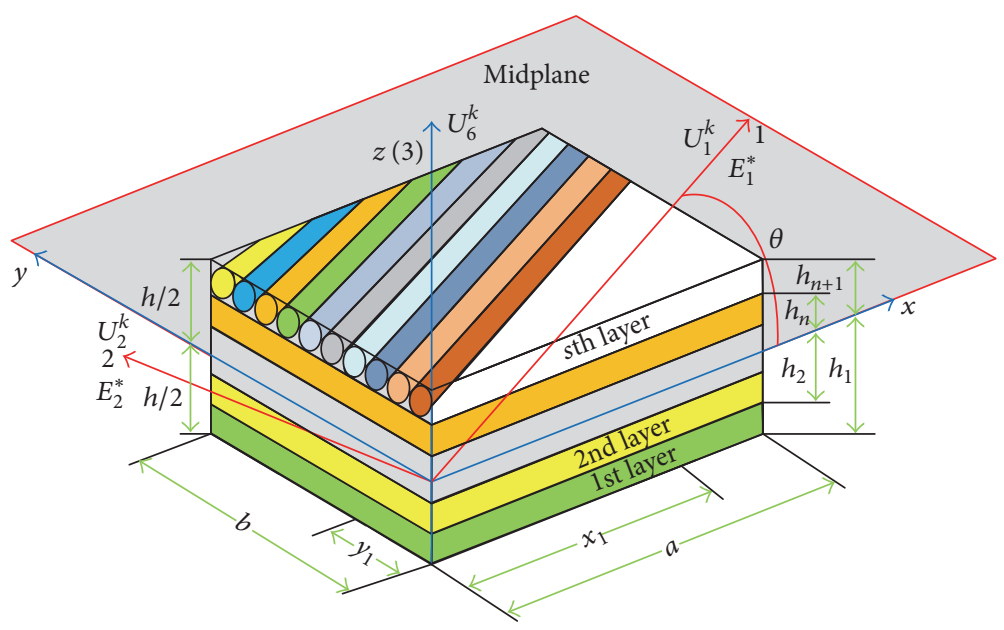

FIGURE 1: Damping model of fiber-reinforced composite thin plate based on complex modulus method.

composite plate is located at $h_{k-1}$ and $h_{k}$ along the $z$-axis with equal thickness of $h_{i}$. In this theoretical model, "1" represents the direction parallel to the fiber, while " 2 " is the direction perpendicular to the fiber, and " 3 " is direction perpendicular to the 1-2 surface. Assuming $E_{1}^{*}$ and $E_{2}^{*}$ as the complex elastic moduli of the layer parallel and perpendicular to fiber, respectively, $G_{12}^{*}$ as the complex shear modulus in the 1-2 surface, $v_{12}^{*}$ and $v_{21}^{*}$ as Poisson's ratios which are induced by the stress in " 1 " and " 2 " direction, and $\rho$ as the density of composite plate, the complex elastic modulus in each direction can be respectively expressed as

$$
\begin{aligned}
E_{1}^{*} & =E_{1}\left(1+i \eta_{11}\right) \\
E_{2}^{*} & =E_{2}\left(1+i \eta_{22}\right) \\
G_{12}^{*} & =G_{12}\left(1+i \eta_{12}\right),
\end{aligned}
$$

where, $\eta_{11}, \eta_{22}$, and $\eta_{12}$ are the loss factors of fiber longitudinal, transverse, and shear direction.

The concerned fiber-reinforced composite plate is symmetrical between the middle surfaces, so its inner and outer displacements are decoupled. According to the classical laminate theory, its displacement field can be expressed as

$$
\begin{aligned}
& u^{*}(x, y, z)=u_{0}(x, y) e^{i \omega t}-z \frac{\partial w_{0}(x, y)}{\partial x} e^{i \omega t} \\
& v^{*}(x, y, z)=v_{0}(x, y) e^{i \omega t}-z \frac{\partial w_{0}(x, y)}{\partial y} e^{i \omega t} \\
& w^{*}(x, y, z)=w_{0}(x, y) e^{i \omega t}
\end{aligned}
$$

where “*” is complex, $u^{*}, v^{*}$, and $w^{*}$ are the displacements of any point of composite plates, and $u_{0}, v_{0}$, and $w_{0}$ are the displacement in the midplane. Besides, $\omega$ is the frequency and $t$ is the time.
In the fiber coordinate system, the constitutive equation of the $k$ th layer can be written as

$$
\left\{\begin{array}{l}
\sigma_{1}^{*} \\
\sigma_{2}^{*} \\
\tau_{12}^{*}
\end{array}\right\}^{k}=\left[\begin{array}{ccc}
Q_{11}^{*} & Q_{12}^{*} & 0 \\
Q_{21}^{*} & Q_{22}^{*} & 0 \\
0 & 0 & Q_{66}^{*}
\end{array}\right]^{k}\left\{\begin{array}{c}
\varepsilon_{1}^{*} \\
\varepsilon_{2}^{*} \\
\gamma_{12}^{*}
\end{array}\right\},
$$

where $Q_{p q}^{*}$ is complex stiffness matrix coefficients of the composite plates with $p=1,2,6$ and $q=1,2,6$, whose expression is as follows:

$$
\begin{aligned}
& Q_{11}^{*}=\frac{E_{1}^{*}}{1-v_{12}^{*} v_{21}^{*}}, \\
& Q_{12}^{*}=\frac{v_{12}^{*} E_{2}^{*}}{1-v_{12}^{*} v_{21}^{*}}=\frac{v_{21}^{*} E_{1}^{*}}{1-v_{12}^{*} v_{21}^{*}}, \\
& Q_{22}^{*}=\frac{E_{2}^{*}}{1-v_{12}^{*} v_{21}^{*}}, \\
& Q_{66}^{*}=G_{12}^{*} .
\end{aligned}
$$

The coefficient of complex stiffness includes the real and the imaginary part, therefore, it can be expressed as follows:

$$
Q_{p q}^{*}=Q_{p q}^{\prime}+i Q_{p q}^{\prime \prime}
$$

where $Q_{p q}^{\prime}$ and $Q_{p q}^{\prime \prime}$ are the real part and imaginary part of the complex stiffness matrix coefficient.

Based on the assumed displacement field of the classical laminate theory, the normal strain $\varepsilon_{z}$ and shear strains $\gamma_{y z}$ and $\gamma_{x z}$ of composite plate are equal to zero; that is, $\varepsilon_{z}=$ $\gamma_{y z}=\gamma_{x z}=0$. Considering the relationship between strain 
and displacement, the strain of any point of composite plates can be obtained as

$$
\begin{aligned}
\varepsilon_{x}^{*} & =\frac{\partial u^{*}(x, y, z)}{\partial x}=-z \frac{\partial^{2} w_{0}(x, y)}{\partial x^{2}} e^{i \omega t} \\
\varepsilon_{y}^{*} & =\frac{\partial v^{*}(x, y, z)}{\partial y}=-z \frac{\partial^{2} w_{0}(x, y)}{\partial y^{2}} e^{i \omega t} \\
\gamma_{x y}^{*} & =\frac{\partial v^{*}(x, y, z)}{\partial x}+\frac{\partial u^{*}(x, y, z)}{\partial y}=-2 z \frac{\partial^{2} w_{0}}{\partial x \partial y} e^{i \omega t}
\end{aligned}
$$

The strain energy $U^{k}$ stored in the laminate structure of the $k$ th layer can be expressed as

$$
U^{k}=U_{1}^{k}+U_{2}^{k}+U_{6}^{k},
$$

where, $U_{1}^{k}, U_{2}^{k}$, and $U_{6}^{k}$ are strain energy of the $k$ layer fiber of reinforced plate in the longitudinal, transverse, and thickness direction of fiber, which can be expressed as

$$
\begin{aligned}
& U_{1}^{k}=\frac{1}{2} \int_{x=0}^{a} \int_{y=0}^{b} \int_{h_{k-1}}^{h_{k}} \sigma_{1}^{*} \varepsilon_{1}^{*} \mathrm{~d} x \mathrm{~d} y \mathrm{~d} z \\
& U_{2}^{k}=\frac{1}{2} \int_{x=0}^{a} \int_{y=0}^{b} \int_{h_{k-1}}^{h_{k}} \sigma_{2}^{*} \varepsilon_{2}^{*} \mathrm{~d} x \mathrm{~d} y \mathrm{~d} z \\
& U_{6}^{k}=\frac{1}{2} \int_{x=0}^{a} \int_{y=0}^{b} \int_{h_{k-1}}^{h_{k}} \tau_{12}^{*} \gamma_{12}^{*} \mathrm{~d} x \mathrm{~d} y \mathrm{~d} z .
\end{aligned}
$$

Substitute (3) into relation (8) which yields

$$
\begin{aligned}
& U_{1}^{k}=U_{11}^{k}+U_{12}^{k} \\
& U_{2}^{k}=U_{21}^{k}+U_{22}^{k} \\
& U_{6}^{k}=U_{66}^{k},
\end{aligned}
$$

where

$$
\begin{aligned}
& U_{11}^{k}=\frac{1}{2} \int_{x=0}^{a} \int_{y=0}^{b} \int_{h_{k-1}}^{h_{k}} Q_{11}^{\prime}\left(\varepsilon_{1}^{*}\right)^{2} \mathrm{~d} x \mathrm{~d} y \mathrm{~d} z \\
& U_{12}^{k}=\frac{1}{2} \int_{x=0}^{a} \int_{y=0}^{b} \int_{h_{k-1}}^{h_{k}} Q_{12}^{\prime} \varepsilon_{1}^{*} \varepsilon_{2}^{*} \mathrm{~d} x \mathrm{~d} y \mathrm{~d} z \\
& U_{21}^{k}=U_{12}^{k} \\
& U_{22}^{k}=\frac{1}{2} \int_{x=0}^{a} \int_{y=0}^{b} \int_{h_{k-1}}^{h_{k}} Q_{22}^{\prime}\left(\varepsilon_{2}^{*}\right)^{2} \mathrm{~d} x \mathrm{~d} y \mathrm{~d} z \\
& U_{66}^{k}=\frac{1}{2} \int_{x=0}^{a} \int_{y=0}^{b} \int_{h_{k-1}}^{h_{k}} Q_{66}^{\prime}\left(\gamma_{12}^{*}\right)^{2} \mathrm{~d} x \mathrm{~d} y \mathrm{~d} z .
\end{aligned}
$$

The strains $\varepsilon_{1}^{*}, \varepsilon_{2}^{*}$, and $\gamma_{12}^{*}$ are related to the strains $\varepsilon_{x}^{*}, \varepsilon_{y}^{*}$, and $\varepsilon_{x y}^{*}$ expressed in the geometric directions according to the strain transformation relation:

$$
\left[\begin{array}{c}
\varepsilon_{1}^{*} \\
\varepsilon_{2}^{*} \\
\gamma_{12}^{*}
\end{array}\right]=\left[\begin{array}{ccc}
m^{2} & n^{2} & m n \\
n^{2} & m^{2} & -m n \\
-2 m n & 2 m n & m^{2}-n^{2}
\end{array}\right]\left[\begin{array}{c}
\varepsilon_{x}^{*} \\
\varepsilon_{y}^{*} \\
\gamma_{x y}^{*}
\end{array}\right],
$$

Substitution of (11) into relation (10) results in

$$
\begin{aligned}
U_{11}^{k} & =\frac{1}{2} \int_{0}^{a} \int_{0}^{b} \int_{h_{k-1}}^{h_{k}} Q_{11}^{\prime}\left(\varepsilon_{x}^{2} m^{4}+\gamma_{x y}^{2} n^{2} m^{2}\right. \\
& +2 \varepsilon_{x} \varepsilon_{y} n^{2} m^{2}+2 \varepsilon_{x} \gamma_{x y} n m^{3}+2 \varepsilon_{y} \gamma_{x y} n^{3} m \\
& \left.+\varepsilon_{y}^{2} n^{4}\right) \mathrm{d} x \mathrm{~d} y \mathrm{~d} z \\
U_{12}^{k} & =\frac{1}{2} \int_{0}^{a} \int_{0}^{b} \int_{h_{k-1}}^{h_{k}} Q_{12}^{\prime}\left[\varepsilon_{x}^{2} n^{2} m^{2}+\varepsilon_{y}^{2} n^{2} m^{2}-\gamma_{x y}^{2} n^{2} m^{2}\right. \\
& +\varepsilon_{x} \varepsilon_{y}\left(n^{4}+m^{4}\right)+\varepsilon_{x} \gamma_{x y}\left(n^{2}-m^{2}\right) n m \\
& \left.+\varepsilon_{y} \gamma_{x y}\left(m^{2}-n^{2}\right) n m\right] \mathrm{d} x \mathrm{~d} y \mathrm{~d} z \\
U_{22}^{k} & =\frac{1}{2} \int_{0}^{a} \int_{0}^{b} \int_{h_{k-1}}^{h_{k}} Q_{22}^{\prime}\left(\varepsilon_{x}^{2} n^{4}+\gamma_{x y}^{2} n^{2} m^{2}+2 \varepsilon_{x} \varepsilon_{y} n^{2} m^{2}\right. \\
& -2 \varepsilon_{x} \gamma_{x y} n^{3} m-2 \varepsilon_{y} \gamma_{x y} n m^{3} \\
& \left.+\varepsilon_{y}^{2} m^{4}\right) \mathrm{d} x \mathrm{~d} y \mathrm{~d} z \\
& \left.+\gamma_{x y}^{2}\left(m^{2}-n^{2}\right)^{2}\right] \mathrm{d} x \mathrm{~d} y \mathrm{~d} z . \\
U_{66}^{k} & =\frac{1}{2} \int_{0}^{a} \int_{0}^{b} \int_{h_{k-1}}^{h_{k}} Q_{66}^{\prime}\left[4\left(\varepsilon_{x}^{2}+\varepsilon_{y}^{2}-2 \varepsilon_{x} \varepsilon_{y}\right) n^{2} m^{2}\right. \\
& 4\left(\varepsilon_{x y}-\varepsilon_{x} \gamma_{x y}\right)\left(m^{2}-n^{2}\right) n m
\end{aligned}
$$

The total in-plane strain energies stored in the layers can thus be obtained by summation of strain energies of all the layers:

$$
\begin{aligned}
& U_{11}=\sum_{k=1}^{s} U_{11}^{k}, \\
& U_{12}=\sum_{k=1}^{s} U_{12}^{k} \\
& U_{22}=\sum_{k=1}^{s} U_{22}^{k}, \\
& U_{66}=\sum_{k=1}^{s} U_{66}^{k} .
\end{aligned}
$$

The relationship between the total strain energy $U$ and strain energy values of fiber-reinforced composite plate $U_{11}$, $U_{12}, U_{22}$, and $U_{66}$ can be written as

$$
U=U_{11}+2 U_{12}+U_{22}+U_{66}
$$

The total dissipated energy of fiber-reinforced composite plates is expressed as

$$
\Delta U=\Delta U_{11}+2 \Delta U_{12}+\Delta U_{22}+\Delta U_{66} \text {, }
$$


where the expression $\Delta U_{p q}$ is as follows:

$$
\begin{aligned}
& \Delta U_{11}=\pi \sum_{k=1}^{s} \int_{0}^{a} \int_{0}^{b} \int_{h_{k-1}}^{h_{k}} Q_{11}^{\prime \prime}\left(\varepsilon_{x}^{2} m^{4}+\gamma_{x y}^{2} n^{2} m^{2}\right. \\
& +2 \varepsilon_{x} \varepsilon_{y} n^{2} m^{2}+2 \varepsilon_{x} \gamma_{x y} n m^{3}+2 \varepsilon_{y} \gamma_{x y} n^{3} m \\
& \left.+\varepsilon_{y}^{2} n^{4}\right) \mathrm{d} x \mathrm{~d} y \mathrm{~d} z \\
& \Delta U_{12}=\pi \sum_{k=1}^{s} \int_{0}^{a} \int_{0}^{b} \int_{h_{k-1}}^{h_{k}} Q_{12}^{\prime \prime}\left[\varepsilon_{x}^{2} n^{2} m^{2}+\varepsilon_{y}^{2} n^{2} m^{2}\right. \\
& -\gamma_{x y}^{2} n^{2} m^{2}+\varepsilon_{x} \varepsilon_{y}\left(n^{4}+m^{4}\right)+\varepsilon_{x} \gamma_{x y}\left(n^{2}-m^{2}\right) n m \\
& \left.+\varepsilon_{y} \gamma_{x y}\left(m^{2}-n^{2}\right) n m\right] \mathrm{d} x \mathrm{~d} y \mathrm{~d} z \\
& \Delta U_{22}=\pi \sum_{k=1}^{s} \int_{0}^{a} \int_{0}^{b} \int_{h_{k-1}}^{h_{k}} Q_{22}^{\prime \prime}\left(\varepsilon_{x}^{2} n^{4}+\gamma_{x y}^{2} n^{2} m^{2}\right. \\
& +2 \varepsilon_{x} \varepsilon_{y} n^{2} m^{2}-2 \varepsilon_{x} \gamma_{x y} n^{3} m-2 \varepsilon_{y} \gamma_{x y} n m^{3} \\
& \left.+\varepsilon_{y}^{2} m^{4}\right) \mathrm{d} x \mathrm{~d} y \mathrm{~d} z \\
& \Delta U_{66}=\pi \sum_{k=1}^{s} \int_{0}^{a} \int_{0}^{b} \\
& \cdot \int_{h_{k-1}}^{h_{k}} Q_{66}^{\prime \prime}\left[4\left(\varepsilon_{x}^{2}+\varepsilon_{y}^{2}-2 \varepsilon_{x} \varepsilon_{y}\right) n^{2} m^{2}\right. \\
& +4\left(\varepsilon_{y} \gamma_{x y}-\varepsilon_{x} \gamma_{x y}\right)\left(m^{2}-n^{2}\right) n m \\
& \left.+\gamma_{x y}^{2}\left(m^{2}-n^{2}\right)^{2}\right] \mathrm{d} x \mathrm{~d} y \mathrm{~d} z \text {. }
\end{aligned}
$$

According to the definition of the specific damping capacity $\psi$ of fiber-reinforced composite plate, it can be expressed as

$$
\psi=\frac{\Delta U}{U} .
$$

Generally, the relationship between the specific damping capacity and structural damping ratio can be expressed as

$$
\psi=4 \pi \xi
$$

By substituting (18) into (17), the relationship between the strain energy and the damping ratio of the fiber-reinforced composite plate can be expressed as

$$
\xi=\frac{\Delta U}{4 \pi U}=\frac{\Delta U_{11}+2 \Delta U_{12}+\Delta U_{22}+\Delta U_{66}}{4 \pi\left(U_{11}+2 U_{12}+U_{22}+U_{66}\right)} .
$$

In this way, the relationship between the material loss factors $\eta_{11}, \eta_{22}$, and $\eta_{12}$ and the damping ratio is established, based on (19).

2.2. Theoretical Calculation of Modal Damping Ratio of Composite Thin Plate. We assume the midplane displacement of composite plate is $w_{0}$, and it can be expressed as

$$
w_{0}=W(\alpha, \beta) e^{i \omega t}
$$

where $\omega$ is the excitation frequency and $W(\xi, \eta)$ is modal shape function which can be defined as

$$
W(\alpha, \beta)=\sum_{d=1}^{D} \sum_{f=1}^{F} a_{d f} P_{d}(\alpha) P_{f}(\beta),
$$

where $a_{d f}$ are the eigenvectors which need to be solved and $P_{d}(\alpha)(d=1, \ldots, D)$ and $P_{f}(\beta)(f=1, \ldots, F)$ are the orthogonal polynomials.

The orthogonal polynomials can be obtained by implementing orthogonalization operation on polynomial function which should satisfy the boundary condition of composite plate, and these polynomials have the following expressions:

$$
\begin{aligned}
P_{1}(\alpha) & =\chi(\alpha), \\
P_{1}(\beta) & =\kappa(\beta) \\
P_{2}(\psi) & =\left(\psi-B_{2}\right) P_{1}(\psi) \\
P_{\lambda}(\psi) & =\left(\psi-B_{\lambda}\right) P_{\lambda-1}(\psi)-C_{\lambda} P_{\lambda-2}(\psi) \\
\psi & =\alpha, \beta, \lambda>2,
\end{aligned}
$$

where $B_{\lambda}$ and $C_{\lambda}$ are the coefficient functions and their expressions can be written as

$$
\begin{aligned}
B_{\lambda} & =\frac{\int_{0}^{1} W(\psi)\left[P_{\lambda-1}(\psi)\right]^{2} \psi \mathrm{d} \psi}{\int_{0}^{1} W(\psi)\left[P_{\lambda-1}(\psi)\right]^{2} \mathrm{~d} \psi} \\
C_{\lambda} & =\frac{\int_{0}^{1} W(\psi) P_{\lambda-1}(\psi) P_{\lambda-2}(\psi) \psi \mathrm{d} \psi}{\int_{0}^{1} W(\psi)\left[P_{\lambda-2}(\psi)\right]^{2} \mathrm{~d} \psi}, \quad \psi=\alpha, \beta,
\end{aligned}
$$

where $W(\psi)$ is the weighting function and generally $W(\psi)=$ 1. Moreover, $\chi(\alpha)$ and $\kappa(\beta)$ are polynomial functions which can satisfy different boundary conditions, such as the clamped, simply supported, and free boundary, and they can be expressed as

$$
\begin{aligned}
& \chi(\alpha)=\alpha^{p}(1-\alpha)^{q}, \\
& \kappa(\beta)=\beta^{r}(1-\beta)^{j} \\
& \alpha=\frac{x}{a}, \beta=\frac{y}{b} .
\end{aligned}
$$

Considering that the studied composite plate is under free boundary condition, the four parameters are given by $p=0, r=0, q=0$, and $j=0$. The damping can be neglected, considering that it has little influence on natural frequency; therefore, only the real part is calculated in the stress-strain constitutive equation (3). The kinetic energy of bending vibration of thin plates can be expressed as

$$
T=\frac{1}{2} \int_{A} \int_{-h / 2}^{h / 2} \rho\left(\frac{\partial w}{\partial t}\right)^{2} \mathrm{~d} A \mathrm{~d} z .
$$

Substitute (19) into (15), then the expression of kinetic energy expressed by undetermined parameters $a_{d f}$ can be 
obtained. Set the harmonic components in kinetic energy $e^{i \omega t}$ to be 1 , and the expression of the maximum kinetic energy can be derived as

$$
T_{\max }=\frac{\rho h \omega^{2}}{2} \iint_{A}(W)^{2} \mathrm{~d} A .
$$

Similarly, the strain energy in (14) is also expressed by the undetermined parameters $a_{d f}$. Set the harmonic component of the strain energy $e^{i \omega t}$ to be 1 , and the expression of the maximum strain energy can be obtained. Next, the Lagrangian energy function $L$ is expressed as

$$
L=T_{\max }-U_{\max }
$$

In the same way to solve the inherent characteristics of fiber-reinforced composite thin plate, all pending parameters that making the Lagrangian energy function $L$ with respect to $a_{d f}$ have the minimum value can be solved; then the following expression is obtained:

$$
\frac{\partial L}{\partial a_{d f}}=0, \quad d=1,2, \ldots, D, f=1,2, \ldots, F
$$

Consequently, the result obtained leads to $M \times N$ equations in frequency domain which can be written as the matrix form:

$$
\left(\mathbf{K}-\omega^{2} \mathbf{M}\right) \mathbf{q}=0,
$$

where $\mathbf{K}$ and $\mathbf{M}$ are the stiffness matrix and mass matrix, respectively, and $\mathbf{q}=\left(q_{11}, q_{12}, \ldots, q_{d f}\right)^{T}$ is the generalized displacement vector.

The elements in $\mathbf{K}$ and $\mathbf{M}$ are coefficients of all pending parameters. In order to make (32) have nonzero solution or nontrivial solution, the determinant of the coefficient matrix should be equal to zero:

$$
\operatorname{det}\left(\mathbf{K}-\omega^{2} \mathbf{M}\right)=0
$$

In this way, the natural frequency of each mode can be obtained. In (21), the larger the values of $D, F$, the more accurate the calculated results of natural frequency, and $D=F=8$ can usually satisfy sufficient accuracy. Meanwhile, substitution of the eigenvectors $\mathbf{a}=\left(a_{11}, a_{12}, \ldots, a_{d f}\right)^{T}$ which correspond to each natural frequency $\omega$ into (21) can lead to the modal shapes. Moreover, substitution of the modal shape function into (20) can lead to the midplane displacement $w_{0}(x, y)$ of the composite plate.

Substitution of (6) into (13) leads to the relationship expression between midplane displacement $w_{0}(x, y)$ and strain energy of the composite plate.

$$
\begin{aligned}
U_{11} & =\frac{1}{2} \sum_{k=1}^{s} \int_{0}^{a} \int_{0}^{b} \int_{h_{k-1}}^{h_{k}} Q_{11}^{\prime}\left[z^{2}\left(\frac{\partial^{2} w_{0}}{\partial x^{2}}\right)^{2} m^{4}\right. \\
& +4 z^{2}\left(\frac{\partial^{2} w_{0}}{\partial x \partial y}\right)^{2} n^{2} m^{2}+2 z^{2} \frac{\partial^{2} w_{0}}{\partial x^{2}} \frac{\partial^{2} w_{0}}{\partial y^{2}} n^{2} m^{2}
\end{aligned}
$$

$$
\begin{aligned}
& +4 z^{2} \frac{\partial^{2} w_{0}}{\partial x^{2}} \frac{\partial^{2} w_{0}}{\partial x \partial y} n m^{3}+4 z^{2} \frac{\partial^{2} w_{0}}{\partial y^{2}} \frac{\partial^{2} w_{0}}{\partial x \partial y} n^{3} m \\
& \left.+z^{2}\left(\frac{\partial^{2} w_{0}}{\partial y^{2}}\right)^{2} n^{4}\right] \mathrm{d} x \mathrm{~d} y \mathrm{~d} z \\
& U_{12}=\frac{1}{2} \sum_{k=1}^{s} \int_{0}^{a} \int_{0}^{b} \int_{h_{k-1}}^{h_{k}} Q_{12}^{\prime}\left[z^{2}\left(\frac{\partial^{2} w_{0}}{\partial x^{2}}\right)^{2} n^{2} m^{2}\right. \\
& +z^{2} \frac{\partial^{2} w_{0}}{\partial x^{2}} \frac{\partial^{2} w_{0}}{\partial y^{2}}\left(n^{4}+m^{4}\right)+2 z^{2} \frac{\partial^{2} w_{0}}{\partial x^{2}} \frac{\partial^{2} w_{0}}{\partial x \partial y}\left(n^{2}\right. \\
& \left.-m^{2}\right) n m+2 z^{2} \frac{\partial^{2} w_{0}}{\partial y^{2}} \frac{\partial^{2} w_{0}}{\partial x \partial y}\left(m^{2}-n^{2}\right) n m \\
& -4 z^{2}\left(\frac{\partial^{2} w_{0}}{\partial x \partial y}\right)^{2} n^{2} m^{2}+z^{2}\left(\frac{\partial^{2} w_{0}}{\partial y^{2}}\right)^{2} \\
& \left.\cdot n^{2} m^{2}\right] \mathrm{d} x \mathrm{~d} y \mathrm{~d} z \\
& U_{22}=\frac{1}{2} \sum_{k=1}^{s} \int_{0}^{a} \int_{0}^{b} \int_{h_{k-1}}^{h_{k}} Q_{22}^{\prime}\left[z^{2}\left(\frac{\partial^{2} w_{0}}{\partial x^{2}}\right)^{2} n^{4}\right. \\
& +4 z^{2}\left(\frac{\partial^{2} w_{0}}{\partial x \partial y}\right)^{2} n^{2} m^{2}+2 z^{2} \frac{\partial^{2} w_{0}}{\partial x^{2}} \frac{\partial^{2} w_{0}}{\partial y^{2}} n^{2} m^{2} \\
& -4 z^{2} \frac{\partial^{2} w_{0}}{\partial x^{2}} \frac{\partial^{2} w_{0}}{\partial x \partial y} n^{3} m-4 z^{2} \frac{\partial^{2} w_{0}}{\partial y^{2}} \frac{\partial^{2} w_{0}}{\partial x \partial y} n m^{3} \\
& \left.+z^{2}\left(\frac{\partial^{2} w_{0}}{\partial y^{2}}\right)^{2} m^{4}\right] \mathrm{d} x \mathrm{~d} y \mathrm{~d} z \\
& U_{66}=\frac{1}{2} \sum_{k=1}^{s} \int_{0}^{a} \int_{0}^{b} \int_{h_{k-1}}^{h_{k}} Q_{66}^{\prime}\left[4 \left(z^{2}\left(\frac{\partial^{2} w_{0}}{\partial x^{2}}\right)^{2}\right.\right. \\
& \left.+z^{2}\left(\frac{\partial^{2} w_{0}}{\partial y^{2}}\right)^{2}-2 z^{2} \frac{\partial^{2} w_{0}}{\partial x^{2}} \frac{\partial^{2} w_{0}}{\partial y^{2}}\right) n^{2} m^{2} \\
& +8 z^{2} \frac{\partial^{2} w_{0}}{\partial x \partial y}\left(\frac{\partial^{2} w_{0}}{\partial y^{2}}-\frac{\partial^{2} w_{0}}{\partial x^{2}}\right)\left(m^{2}-n^{2}\right) n m \\
& \left.+4 z^{2}\left(\frac{\partial^{2} w_{0}}{\partial x \partial y}\right)^{2}\left(m^{2}-n^{2}\right)^{2}\right] \mathrm{d} x \mathrm{~d} y \mathrm{~d} z .
\end{aligned}
$$

Substitution of (6) into (13) leads to the relationship expression between midplane displacement $w_{0}(x, y)$ and dissipated energy of the composite plate.

$$
\begin{array}{r}
\Delta U_{11}=\pi \sum_{k=1}^{s} \int_{0}^{a} \int_{0}^{b} \int_{h_{k-1}}^{h_{k}} Q_{11}^{\prime \prime}\left[z^{2}\left(\frac{\partial^{2} w_{0}}{\partial x^{2}}\right)^{2} m^{4}\right. \\
+4 z^{2}\left(\frac{\partial^{2} w_{0}}{\partial x \partial y}\right)^{2} n^{2} m^{2}+2 z^{2} \frac{\partial^{2} w_{0}}{\partial x^{2}} \frac{\partial^{2} w_{0}}{\partial y^{2}} n^{2} m^{2}
\end{array}
$$




$$
\begin{aligned}
& +4 z^{2} \frac{\partial^{2} w_{0}}{\partial x^{2}} \frac{\partial^{2} w_{0}}{\partial x \partial y} n m^{3}+4 z^{2} \frac{\partial^{2} w_{0}}{\partial y^{2}} \frac{\partial^{2} w_{0}}{\partial x \partial y} n^{3} m \\
& \left.+z^{2}\left(\frac{\partial^{2} w_{0}}{\partial y^{2}}\right)^{2} n^{4}\right] \mathrm{d} x \mathrm{~d} y \mathrm{~d} z \\
& \Delta U_{12}=\pi \sum_{k=1}^{s} \int_{0}^{a} \int_{0}^{b} \int_{h_{k-1}}^{h_{k}} Q_{12}^{\prime \prime}\left[z^{2}\left(\frac{\partial^{2} w_{0}}{\partial x^{2}}\right)^{2} n^{2} m^{2}\right. \\
& +z^{2} \frac{\partial^{2} w_{0}}{\partial x^{2}} \frac{\partial^{2} w_{0}}{\partial y^{2}}\left(n^{4}+m^{4}\right)+2 z^{2} \frac{\partial^{2} w_{0}}{\partial x^{2}} \frac{\partial^{2} w_{0}}{\partial x \partial y}\left(n^{2}\right. \\
& \left.-m^{2}\right) n m+2 z^{2} \frac{\partial^{2} w_{0}}{\partial y^{2}} \frac{\partial^{2} w_{0}}{\partial x \partial y}\left(m^{2}-n^{2}\right) n m \\
& -4 z^{2}\left(\frac{\partial^{2} w_{0}}{\partial x \partial y}\right)^{2} n^{2} m^{2}+z^{2}\left(\frac{\partial^{2} w_{0}}{\partial y^{2}}\right)^{2} \\
& \left.\cdot n^{2} m^{2}\right] \mathrm{d} x \mathrm{~d} y \mathrm{~d} z \\
& \Delta U_{22}=\pi \sum_{k=1}^{s} \int_{0}^{a} \int_{0}^{b} \int_{h_{k-1}}^{h_{k}} Q_{22}^{\prime \prime}\left[z^{2}\left(\frac{\partial^{2} w_{0}}{\partial x^{2}}\right)^{2} n^{4}\right. \\
& +4 z^{2}\left(\frac{\partial^{2} w_{0}}{\partial x \partial y}\right)^{2} n^{2} m^{2}+2 z^{2} \frac{\partial^{2} w_{0}}{\partial x^{2}} \frac{\partial^{2} w_{0}}{\partial y^{2}} n^{2} m^{2} \\
& -4 z^{2} \frac{\partial^{2} w_{0}}{\partial x^{2}} \frac{\partial^{2} w_{0}}{\partial x \partial y} n^{3} m-4 z^{2} \frac{\partial^{2} w_{0}}{\partial y^{2}} \frac{\partial^{2} w_{0}}{\partial x \partial y} n m^{3} \\
& \left.+z^{2}\left(\frac{\partial^{2} w_{0}}{\partial y^{2}}\right)^{2} m^{4}\right] \mathrm{d} x \mathrm{~d} y \mathrm{~d} z \\
& \Delta U_{66}=\pi \sum_{k=1}^{s} \int_{0}^{a} \int_{0}^{b} \int_{h_{k-1}}^{h_{k}} Q_{66}^{\prime \prime}\left[4 \left(z^{2}\left(\frac{\partial^{2} w_{0}}{\partial x^{2}}\right)^{2}\right.\right. \\
& \left.+z^{2}\left(\frac{\partial^{2} w_{0}}{\partial y^{2}}\right)^{2}-2 z^{2} \frac{\partial^{2} w_{0}}{\partial x^{2}} \frac{\partial^{2} w_{0}}{\partial y^{2}}\right) n^{2} m^{2} \\
& +8 z^{2} \frac{\partial^{2} w_{0}}{\partial x \partial y}\left(\frac{\partial^{2} w_{0}}{\partial y^{2}}-\frac{\partial^{2} w_{0}}{\partial x^{2}}\right)\left(m^{2}-n^{2}\right) n m \\
& \left.+4 z^{2}\left(\frac{\partial^{2} w_{0}}{\partial x \partial y}\right)^{2}\left(m^{2}-n^{2}\right)^{2}\right] \mathrm{d} x \mathrm{~d} y \mathrm{~d} z .
\end{aligned}
$$

The strain energy and dissipation energy of the composite plate are obtained by substituting midplane displacement $w_{0}(x, y)$ which is related to each natural frequency into (31) and (32). Then, substitute the above results into (19), and we can determine the functional relation between the material loss factors $\eta_{11}, \eta_{22}$, and $\eta_{12}$ and the modal damping ratio.

2.3. Identification of Loss Factor of Composite Thin Plate Based on Least Square Method. Because the dissipated energy $\Delta U$ of the composite plate is a function of loss factors $\eta_{11}, \eta_{22}$, and $\eta_{12}$, according to the relationship between damping ratio, strain energy, and dissipation energy in (19), it can be found that the modal damping ratio $\xi_{i}$ of composite plates is also the function of loss factors. The least square method is used to solve the loss factor because its algorithm is simple and highly efficient. Firstly, the damping ratio of composite plate is obtained by (19) and the experimental test within a certain frequency band, and the relative error function is established as

$$
e=\sum_{i=1}^{R}\left(\frac{\left|\Delta \xi_{i}\right|}{\widehat{\xi}_{i}}\right)^{2},
$$

where $R$ is the number of modes included in the frequency band and $\Delta \xi_{i}$ is the $i$ th difference for damping ratio between theoretical calculation and experimental results, while $\widehat{\xi}_{i}$ is the $i$ th damping ratio obtained by experimental test.

The value of loss factors of fiber-reinforced composite plate is generally less than $10 \%$, and therefore, the material loss factor can be given as

$$
\begin{aligned}
& 0 \leq \eta_{11} \leq 10 \% \\
& 0 \leq \eta_{22} \leq 10 \% \\
& 0 \leq \eta_{12} \leq 10 \% .
\end{aligned}
$$

Select the appropriate step-size $g$ (e.g., $g=0.01 \%$ ) to construct the material loss factor vectors $\boldsymbol{\eta}_{11}, \boldsymbol{\eta}_{22}$, and $\boldsymbol{\eta}_{12}$, which can be expressed as

$$
\begin{aligned}
& \boldsymbol{\eta}_{11}=\left[\begin{array}{lllll}
\eta_{11}^{1} & \eta_{11}^{2} & \eta_{11}^{3} & \cdots & \eta_{11}^{n}
\end{array}\right] \\
& \boldsymbol{\eta}_{22}=\left[\begin{array}{lllll}
\eta_{22}^{1} & \eta_{22}^{2} & \eta_{22}^{3} & \cdots & \eta_{22}^{n}
\end{array}\right] \\
& \boldsymbol{\eta}_{12}=\left[\begin{array}{lllll}
\eta_{12}^{1} & \eta_{12}^{2} & \eta_{12}^{3} & \cdots & \eta_{12}^{n}
\end{array}\right],
\end{aligned}
$$

where $\eta_{i j}^{1}=0$, and $\eta_{i j}^{2}=g, \ldots, \eta_{i j}^{n}=(n-1) g$.

Then, by iteratively solving the material loss factor in a permutation and combination manner, we can identify the desired loss factor along the longitudinal, transverse, and shear direction of fiber-reinforced composite when the relative error function $e$ takes the minimum value.

\section{Identification Procedure}

In Section 2, the identification principle of loss factor of fiberreinforced composite thin plate by using complex modulus method is gradually clarified. In this section, the identification procedure of loss factor of such composite laminates is summarized, and the corresponding identification procedure is realized based on self-designed MATLAB program, which can be divided into the following steps.

(1) Input the Geometric Parameters and Material Parameters of the Composite Plate. Firstly, the geometric parameters such as length, width, thickness, and total number of layers of fiberreinforced composite plate are required. Then, the complex elastic modulus, Poisson's ratio, and density of the composite 
thin plate are individually input to prepare for the subsequent calculation of strain energy and dissipated energy.

(2) Calculate the Mass Matrix and Complex Stiffness Matrix of Composite Plate. The mass matrix and complex stiffness matrix of composite thin plates are calculated, with considering the influence of fiber orientation based on classical laminated plate theory. The value of the complex stiffness matrix of the $k$ th layer of the fiber-reinforced composite plate can be obtained by (4) and substitution of it into (3) leads to the constitutive equation of the composite plate.

(3) Solve the Natural Frequencies and Midplane Displacement of Composite Thin Plate by Using the Ritz Method. The natural frequencies can be obtained by solving the characteristic equation of free vibration of fiber-reinforced composite plates. The stiffness matrix and mass matrix gained from step (2) can lead to the characteristic equation (29). In the case of nonzero solution of (29), the determinant of the coefficient matrix should satisfy (30). Then the natural frequencies can be obtained by solving (30). The mode shapes can be obtained by substituting the eigenvectors $\mathbf{q}=\left(a_{11}, a_{12}, \ldots, a_{d f}\right)^{T}$ which correspond to each natural frequency into (21). Moreover, substitute the mode shape function into (20), and then the midplane displacement of composite thin plate can be obtained.

(4) Obtain Total Strain Energy, Dissipation Energy, and Function of Damping Ratio and Loss Factor. Substitute the midplane displacement $w_{0}(x, y)$ which corresponds to each natural frequency into (31) and (32), and then the strain energy values $U_{11}, U_{12}, U_{22}$, and $U_{66}$ and dissipation energy values $\Delta U_{11}, \Delta U_{12}, \Delta U_{22}$, and $\Delta U_{66}$ can be derived. Next, inputting the above results into (19), the functional relation between the damping ratio of various modes and the loss factors $\eta_{11}, \eta_{22}$, and $\eta_{12}$ can be obtained.

(5) Identify Loss Factor of Composite Thin Plate by Least Square Method. In view of the fact that the value of the loss factor is less than $10 \%$, the appropriate step-size $g$ (e.g., $g=$ $0.01 \%$ ) is selected to construct the material loss factor vectors and identify the loss factor of composite thin plate by least square method based on the damping ratio obtained in a certain frequency band. The value of loss factor is regarded as the best predictor when the least squares error function $e$ takes the minimum value, and identification process of the loss factor of fiber-reinforced composite thin plate is given in Figure 2.

\section{A Study Case}

In this section, a TC300 carbon/epoxy composite plate is taken as a research object, as shown in Figure 3. Its damping parameters are measured under free boundary condition in experiment, and the loss factor of such material is also identified by the complex modulus method. The studied TC300 carbon/epoxy composite plate is symmetrically laid, which has total 21 layers with laminate configuration of $\left[(0 / 90)_{5} / 0 /(90 / 0)_{5}\right]$, and each layer has the same thickness

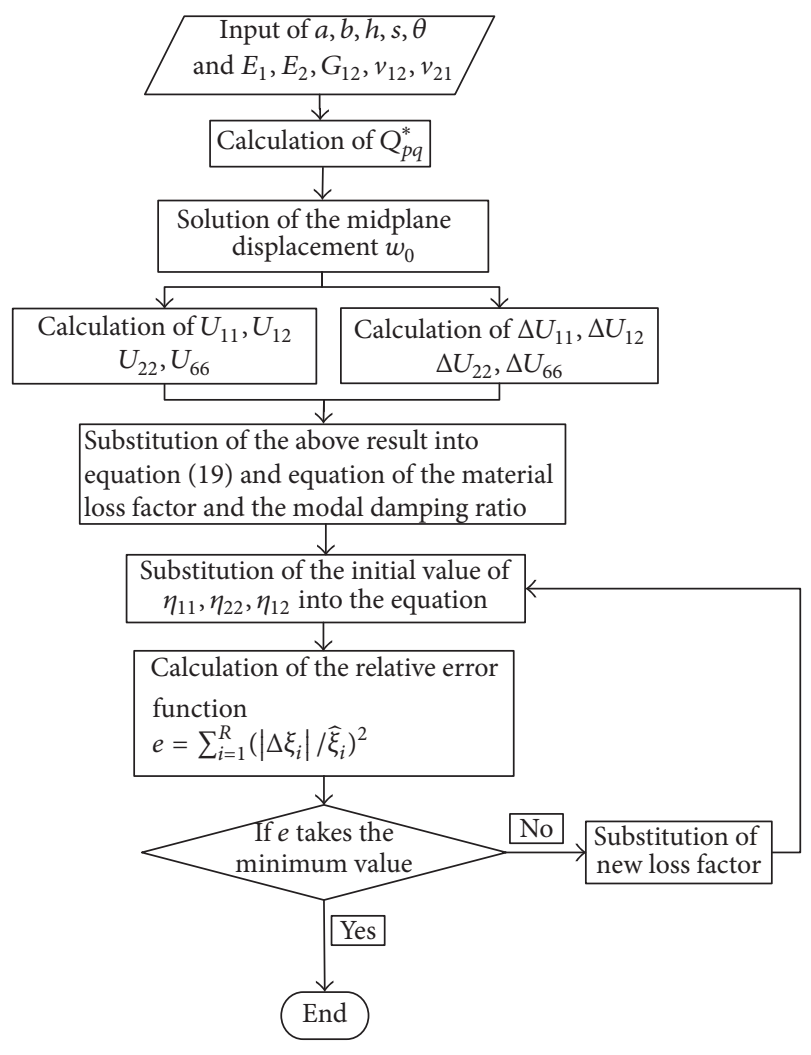

FIGURE 2: Identification process of loss factor of fiber-reinforced composite thin plate based on complex modulus method.

and fiber volume fraction with longitudinal elastic modulus of $E_{1}=136 \mathrm{GPa}$, transverse elastic modulus of $E_{2}=$ $7.92 \mathrm{GPa}$, shear modulus of $G_{12}=3.39 \mathrm{GPa}$, Poisson's ratio of 0.33 , and density of $1780 \mathrm{~kg} / \mathrm{m}^{3}$. Besides, the length, width, and thickness of composite plate are $200 \times 130 \times 2.36 \mathrm{~mm}$.

4.1. Damping Test System and Test Results. The damping test system of composite thin plate is set up, and its connection schematic can be seen in Figure 3. The instruments used in the test are as follows: (I) BK 4517-001 lightweight accelerometer; (II) LMS SCADAS 16-channel mobile front-end; (III) Dell M7700 notebook computer and LMS Test.Lab 10B software; (IV) PCB 086C01Hammer. After the repeated testing and comparison, the accelerometer is glued firmly at reference point $P$ by super glue 502, and the point $P$ is $40 \mathrm{~mm}$ from the left edge and $30 \mathrm{~mm}$ from the downside edge of the composite plate. Then, the following setups and parameters are chosen: (I) sampling frequency of $3200 \mathrm{~Hz}$; (II) frequency resolution of $0.125 \mathrm{~Hz}$; (III) force-exponential window for excitation signal and exponential window for response signals. Consequently, we can employ pulse excitation technique to carry out modal test, and, by analyzing the response signal in frequency domain with LMS software, the natural frequency and the damping ratio of each mode can be obtained with the half-power bandwidth method. The actual photograph of damping test of fiber-reinforced composite thin plate can be seen in Figure 4, and Figure 5 also lists the measured frequency response functions at three different measuring 


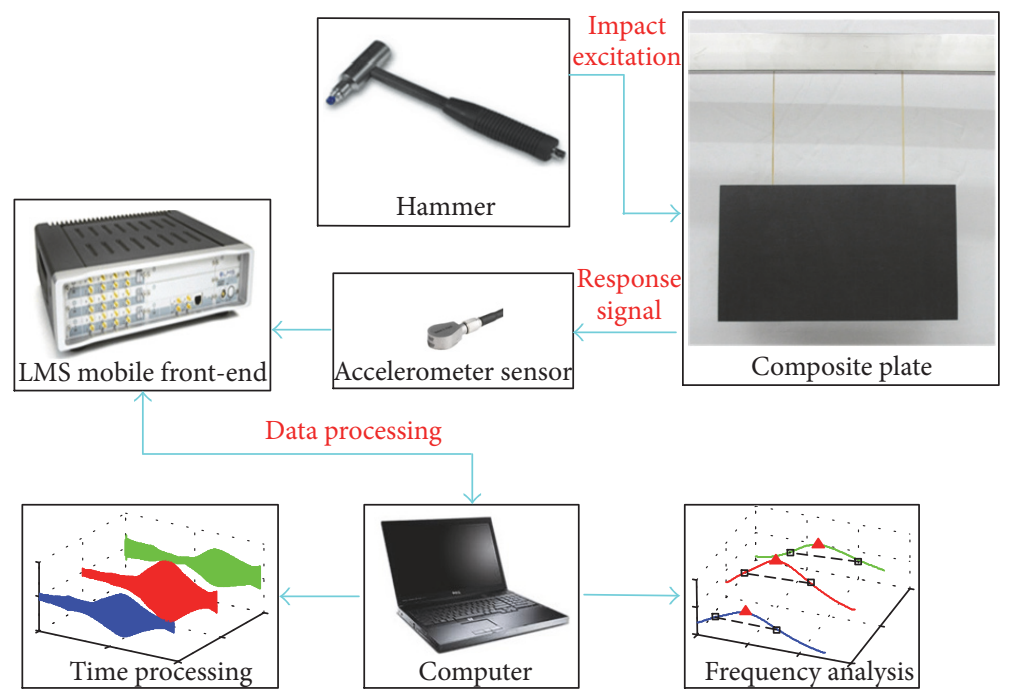

Figure 3: Connection schematic of damping test system of composite thin plate.

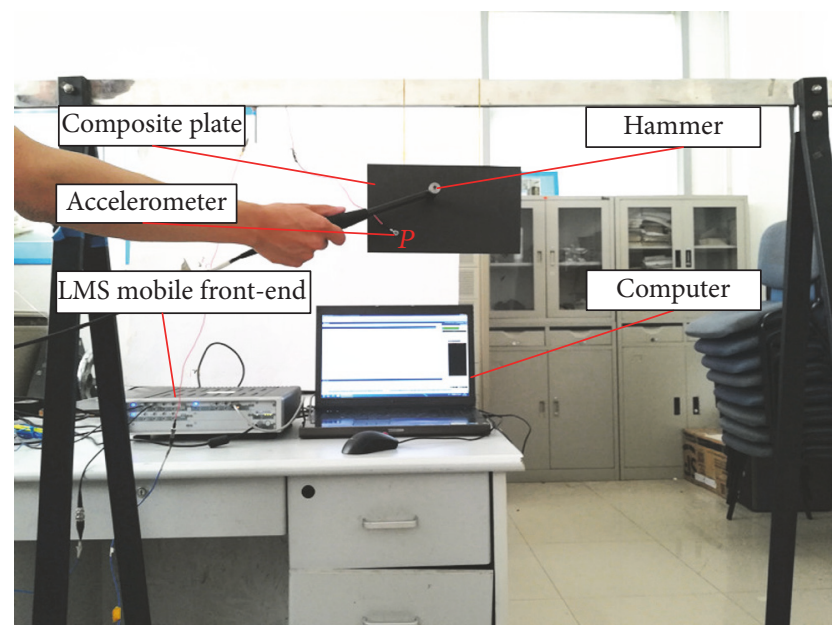

Figure 4: Actual photograph of damping test of fiber-reinforced composite thin plate.

points. In order to improve test accuracy of frequency and damping results, the final results are obtained by averaging the results at these measuring points, which are listed in Table 1.

4.2. Identification Process and Results. By using the identification process in Section 2, the natural frequency of composite thin plate can be calculated according to the elastic modulus and other material parameters given by the manufacturer. Table 2 gives the natural frequencies obtained by such method and also gives the corresponding errors compared with the experimental results. Next, the functional relation between the damping ratio and the loss factor is derived based on (19), and loss factor vector is constructed by selecting the appropriate step-size in the case that loss factor value is less than $10 \%$. Finally, the loss factor of composite thin plate can be identified with least square method. When the least square

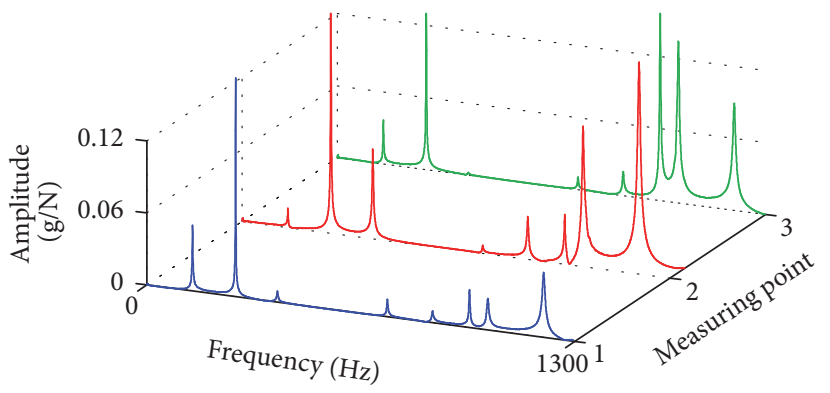

Figure 5: Frequency response functions of composite thin plate obtained at three different measuring points.

error function $e$ (such as $e=0.01024$ ) takes the minimum, the corresponding loss factor can thus be regarded as the desired result.

Because the loss factor of composite thin plate is closely related to the step-size, we set the six different step-sizes, namely, 0.001, 0.0005, 0.0002, 0.0001, 0.00005, and 0.00001, to calculate the concerned loss factor, and Table 3 gives the identified loss factor along the longitudinal, transverse, and shear direction of fiber-reinforced composite obtained by different step-sizes as well as their time expenditure. It can be found that when the value of step-size is less than 0.0001, the loss factor results are basically the same with each other, which can meet the requirement of calculation accuracy. However, the time costs of step-size of 0.00005 and 0.00001 are more than 30 times compared with the corresponding result of step-size of 0.0001 , so we finally choose 0.0001 as the best step-size to identify each loss factor.

Besides, in order to investigate the sensitivity of the identified loss factors with respect to the calculated maximum error of natural frequencies, we deliberately adjust the thickness, elastic modulus, Poisson's ratio and so forth, and the identified loss factors with respect to the different maximum error of natural frequencies are listed in Table 4, from which 
TABLE 1: The first 8 natural frequencies and damping ratios of composite thin plate obtained by experiment.

\begin{tabular}{lcccccccc}
\hline Modal order & 1 & 2 & 3 & 4 & 5 & 6 & 7 & 8 \\
\hline Natural frequency (Hz) & 139.8 & 270.3 & 397.3 & 730.9 & 867.9 & 980.5 & 1035.2 & 1205.9 \\
Damping ratio (\%) & 1.06 & 0.25 & 0.61 & 0.33 & 0.52 & 0.24 & 0.49 & 0.56 \\
\hline
\end{tabular}

TABLE 2: The first 8 natural frequencies obtained by the complex modulus method and its errors.

\begin{tabular}{lcccccccc}
\hline Modal order & 1 & 2 & 3 & 4 & 5 & 6 & 7 & 8 \\
\hline Calculation $(\mathrm{Hz})$ & 139.2 & 278.6 & 357.1 & 742.9 & 835.2 & 985.6 & 1005.1 & 1175.5 \\
Experiment $(\mathrm{Hz})$ & 139.8 & 270.3 & 387.3 & 730.9 & 867.9 & 980.5 & 1035.2 & 1205.9 \\
Errors (\%) & 0.43 & 3.07 & 7.80 & 1.64 & 3.77 & 0.52 & 2.91 & 2.52 \\
\hline
\end{tabular}

TABLE 3: Loss factor of fiber-reinforced composite obtained by different step-size parameters and its time expenditure.

\begin{tabular}{lcccc}
\hline Step-size & $\eta_{11}(\%)$ & $\eta_{22}(\%)$ & $\eta_{12}(\%)$ & Time (s) \\
\hline 0.001 & 0.5 & 0.7 & 2.2 & 0.07 \\
0.0005 & 0.55 & 0.65 & 2.15 & 1.62 \\
0.0002 & 0.54 & 0.64 & 2.14 & 7.95 \\
0.0001 & 0.54 & 0.63 & 2.13 & 56.62 \\
0.00005 & 0.54 & 0.63 & 2.13 & 1830.95 \\
0.00001 & 0.54 & 0.63 & 2.13 & 55864.25 \\
\hline
\end{tabular}

we can see that, with the increase of the calculated maximum error of the first three natural frequencies, the deviations between the identified loss factors would show an increasing tendency. So, in order to ensure that the identified loss factors along the longitudinal, transverse, and shear directions can have better accuracy, we need to improve the calculated accuracy of natural frequencies of composite plate as much as possible, and, in this research, the calculated maximum error of natural frequency based on the established damping model in Section 2 is less than $8 \%$, so it is appropriate to employ this theoretical model to identify the concerned loss factors.

4.3. Verification and Discussion. In order to verify the correctness of the proposed identification method, we also establish the Adams-Bacon damping model based on the theoretical principle described in literature [23] to calculate the modal damping ratio of such composite plate, which can be realized by introducing the loss factor results identified in this paper into the algorithm in literature [23]. And in Table 4 the calculated damping results in literature [23] are listed and, for better comparison of damping results, their deviations between the tested damping ratios in this paper and calculated damping ratios in literature [23] are also given in Table 5.

It can be seen from Table 5 that the modal damping ratio results calculated by the Adams-Bacon damping model can have a good agreement with the corresponding experimental results, and the maximum deviation of modal damping ratios is less than $15 \%$. Therefore, the correctness and effectiveness of the complex modulus method have been verified indirectly, and the complex modulus method can be applied to the analysis and prediction of damping property of fiber-reinforced composites. However, it is still necessary to find out the reasons for the above deviations, which probably result from both theoretical modeling and experimental testing aspects, for example, in the theoretical modeling process, which may contain the following calculation errors: (I) without considering the damping resulting from interfacial friction between layers and the damping resulting from interface defect; (II) without considering the effects of residual stress; (III) without considering the influence of the dispersion of composite material parameters; (IV) without considering the influence of the accumulation of the truncation error and rounding error on the damping results in the calculation process. Meanwhile, in the experimental measurement, the following factors may also lead to some errors: (I) without considering the influence of boundary conditions in the measurement; (II) without considering the influence of additional mass of the lightweight accelerometer; (III) without considering the influence of air damping. Besides, it should be noted that because the premise of identification of loss factor of fiber-reinforced composite by complex modulus method is based on the composite plate model, we need to cut a plate test specimen from the fiber composite material, and if the preparation process parameters of such composite material is changed, including fiber angle, lay-up form, and other variation in configuration, then we need to identify the new loss factors once again, which would somewhat restrict the application of such method in the engineering field. However, the geometrical size of fiber-reinforced composite plate indeed will not affect the identification of loss factor results.

\section{Conclusion}

This research has investigated the identification technique of the loss factor of fiber-reinforced composite, and the following conclusions are obtained.

(1) With the comparison between the measured damping results obtained in this paper and the calculated damping results based on the Adams-Bacon model with the same loss factor, the corresponding maximum deviation between them is less than $15 \%$, so the correctness of complex modulus method has been verified indirectly, which can be used to identify the loss factor of fiber-reinforced composite with high precision and efficiency.

(2) Complex modulus method mainly contains the following key steps: (I) input the geometric parameters and material parameters; (II) calculate the mass matrix and 


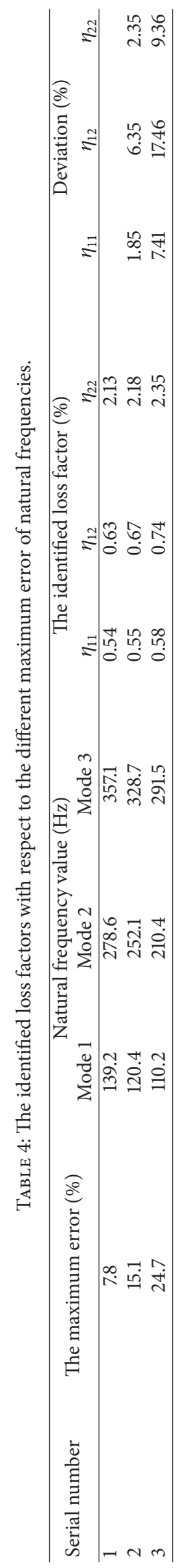


TABLE 5: The tested damping obtained experimentally in this paper and the calculated damping obtained in the literature and their deviations.

\begin{tabular}{lccc}
\hline $\begin{array}{l}\text { Modal } \\
\text { order }\end{array}$ & $\begin{array}{c}\text { Tested damping in } \\
\text { this paper (\%) }\end{array}$ & $\begin{array}{c}\text { Calculated } \\
\text { damping in } \\
\text { literature [23] (\%) }\end{array}$ & $\begin{array}{c}\text { Deviation } \\
(\%)\end{array}$ \\
\hline 1 & 1.06 & 0.97 & 8.49 \\
2 & 0.25 & 0.28 & 12 \\
3 & 0.61 & 0.58 & 4.92 \\
4 & 0.33 & 0.29 & 12.12 \\
5 & 0.52 & 0.59 & 13.46 \\
6 & 0.24 & 0.21 & 12.5 \\
7 & 0.49 & 0.44 & 10.20 \\
8 & 0.56 & 0.48 & 14.29 \\
\hline
\end{tabular}

complex stiffness matrix; (III) solve the natural frequencies and midplane displacement; (IV) obtain total strain energy, dissipation energy, and function of damping ratio and loss factor; (V) identify loss factor by least square method.

(3) In order to ensure that the identified loss factors along the longitudinal, transverse, and shear directions can have better accuracy, the calculated accuracy of natural frequencies of composite plate need to be improved as much as possible. Besides, after comparing with the identified loss factor of fiber-reinforced composite obtained by different step-sizes as well as their time expenditure, it has been found out that the step-size of 0.0001 is the best step-size.

\section{Conflicts of Interest}

The authors declare that there are no conflicts of interest regarding the publication of this article.

\section{Acknowledgments}

This study was supported by the National Natural Science Foundation of China Grant no. 51505070, the Fundamental Research Funds for the Central Universities of China Grant no. N150304011 and no. N160313002, and Key Laboratory of Vibration and Control of Aero-Propulsion System Ministry of Education, Northeastern University, Grant no. VCAME201603.

\section{References}

[1] R. Chandra, S. P. Singh, and K. Gupta, "Damping studies in fiber-reinforced composites-a review," Composite Structures, vol. 46, no. 1, pp. 41-51, 1999.

[2] A. Treviso, B. Van Genechten, D. Mundo, and M. Tournour, "Damping in composite materials: Properties and models," Composites Part B: Engineering, vol. 78, pp. 144-152, 2015.

[3] D. Montalvão, R. A. L. D. Cláudio, A. M. R. Ribeiro, and J. Duarte-Silva, "Experimental measurement of the complex Young's modulus on a CFRP laminate considering the constant hysteretic damping model," Composite Structures, vol. 97, pp. 9198, 2013.

[4] L. Ulke-Winter, M. Klaerner, and L. Kroll, "Determining the damping behavior of fiber reinforced composites: a new approach to find mathematical relationships in data sets," Composite Structures, vol. 100, pp. 34-39, 2013.

[5] L. Dun-xiang, N. Rong-gen, and R. D. Adams, "The finite element technique for predicting the natural frequencies, mode shapes and damping values of filamentary composite plates," Applied Mathematics and Mechanics-English Edition, vol. 7, no. 2, pp. 197-213, 1986.

[6] J.-M. Berthelot, M. Assarar, Y. Sefrani, and A. E. Mahi, "Damping analysis of composite materials and structures," Composite Structures, vol. 85, no. 3, pp. 189-204, 2008.

[7] R. D. Adams and D. G. C. Bacon, "Effect of Fibre Orientation and Laminate Geometry on the Dynamic Properties of CFRP," Journal of Composite Materials, vol. 7, no. 4, pp. 402-428, 1973.

[8] M. D. Rao and S. He, "Dynamic analysis and design of laminated composite beams with multiple damping layers," AIAA Journal, vol. 31, no. 4, pp. 736-745, 1993.

[9] R. Rikards, A. Chate, A. K. Bledzki, and V. Kushnevsky, "Numerical modelling of damping properties of laminated composites," Mechanics of Composite Materials, vol. 30, no. 3, pp. 256-266, 1994.

[10] J. De Visscher, H. Sol, W. P. De Wilde, and J. Vantomme, "Identification of the Damping Properties of Orthotropic Composite Materials Using a Mixed Numerical Experimental Method," Applied Composite Materials, vol. 4, no. 1, pp. 13-33, 1997.

[11] M. Dalenbring, "Experimental material damping estimation for planar isotropic laminate structures," International Journal of Solids and Structures, vol. 39, no. 19, pp. 5053-5079, 2002.

[12] J. D. D. Melo and D. W. Radford, "Viscoelastic characterization of transversely isotropic composite laminae," Journal of Composite Materials, vol. 37, no. 2, pp. 129-146, 2003.

[13] V. Kostopoulos and D. T. Korontzis, "A new method for the determination of viscoelastic properties of composite laminates: A mixed analytical-experimental approach," Composites Science and Technology, vol. 63, no. 10, pp. 1441-1452, 2003.

[14] R. Chandra, S. P. Singh, and K. Gupta, "Experimental evaluation of damping of fiber-reinforced composites," Journal of Composites, Technology and Research, vol. 25, no. 2, pp. 96-107, 2003.

[15] J.-M. Berthelot and Y. Sefrani, "Damping analysis of unidirectional glass and Kevlar fibre composites," Composites Science and Technology, vol. 64, no. 9, pp. 1261-1278, 2004.

[16] J.-M. Berthelot, "Damping analysis of laminated beams and plates using the Ritz method," Composite Structures, vol. 74, no. 2, pp. 186-201, 2006.

[17] P. Kumar, R. Chandra, and S. P. Singh, "Interphase effect on damping in fiber-reinforced composites," ICCES, vol. 4, pp. 6772, 2007.

[18] M. M. Shokrieh and A. Najafi, "Damping characterization and viscoelastic behavior of laminated polymer matrix composites using a modified classical lamination theory," Experimental Mechanics, vol. 47, no. 6, pp. 831-839, 2007.

[19] M. Matter, T. Gmür, J. Cugnoni, and A. Schorderet, "Numericalexperimental identification of the elastic and damping properties in composite plates," Composite Structures, vol. 90, no. 2, pp. 180-187, 2009.

[20] C. Devalve and R. Pitchumani, "Experimental investigation of the damping enhancement in fiber-reinforced composites with carbon nanotubes," Carbon, vol. 63, pp. 71-83, 2013.

[21] R. F. Gibson and R. Plunkett, "Dynamic Mechanical Behavior of Fiber-Reinforced Composites: Measurement and Analysis," Journal of Composite Materials, vol. 10, no. 4, pp. 325-341, 1976. 
[22] R. F. Gibson and R. Plunkett, "A forced-vibration technique for measurement of material damping - Internal damping of beam specimens in resonant flexural vibration is found from measurements of input acceleration and resulting specimenbending strain," Experimental Mechanics, vol. 17, no. 8, pp. 297302, 1977.

[23] R. D. Adams and M. R. Maheri, "Damping in advanced polymer-matrix composites," Journal of Alloys and Compounds, vol. 355, no. 1-2, pp. 126-130, 2003. 


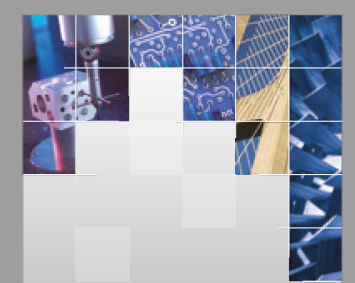

\section{Enfincering}
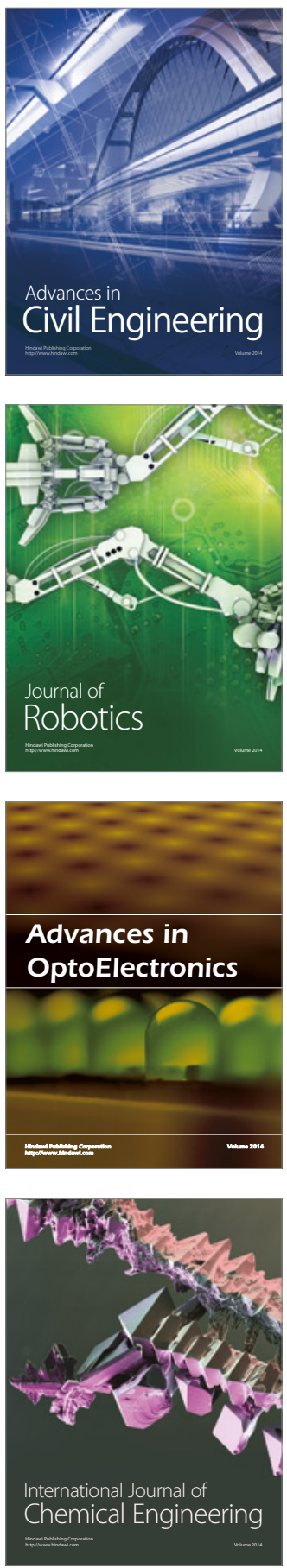

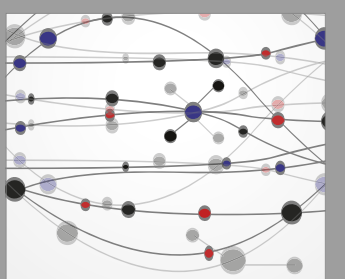

The Scientific World Journal

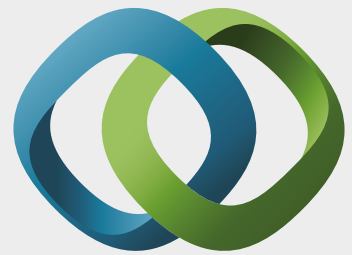

\section{Hindawi}

Submit your manuscripts at

https://www.hindawi.com
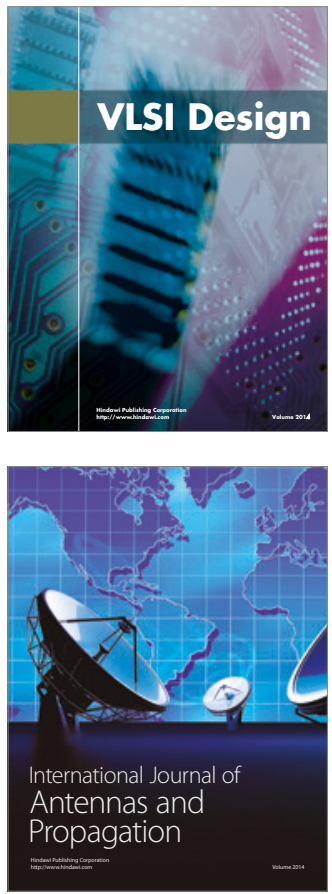

\section{Rotating}

Machinery
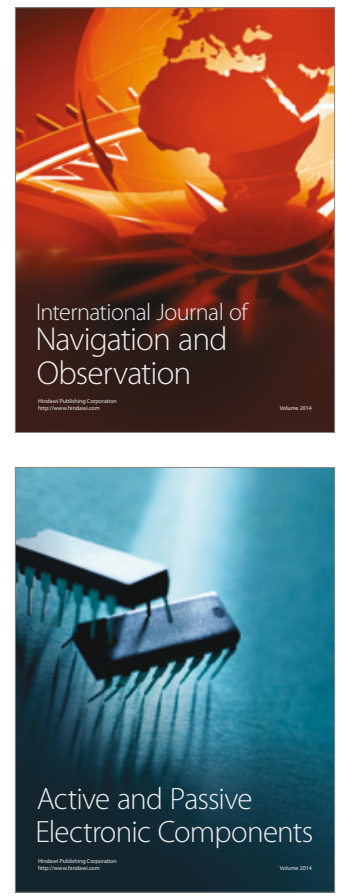
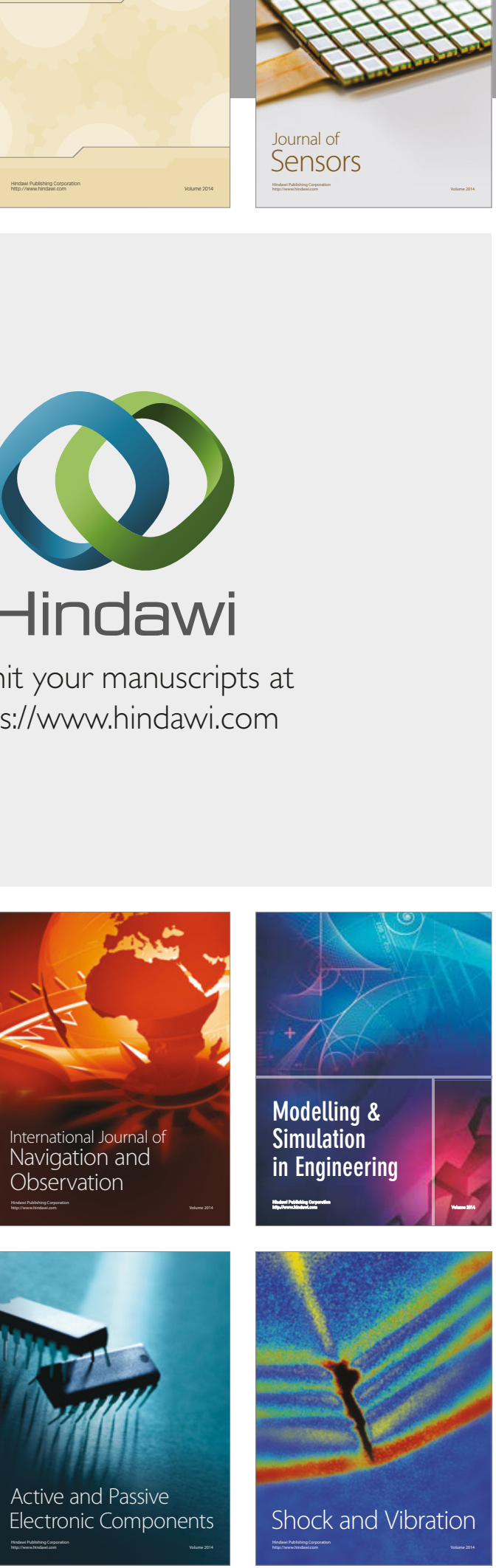
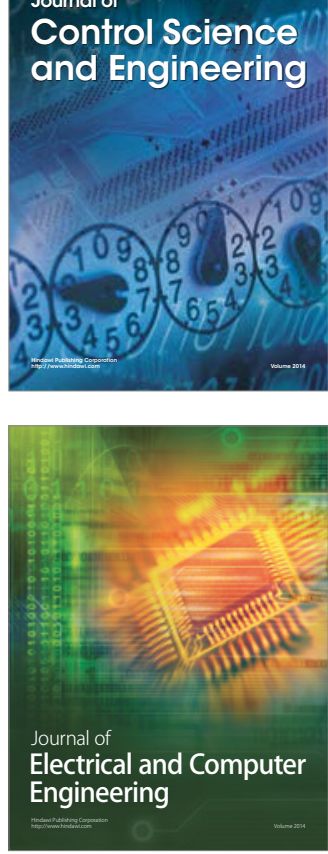

Distributed

Journal of

Control Science

and Engineering
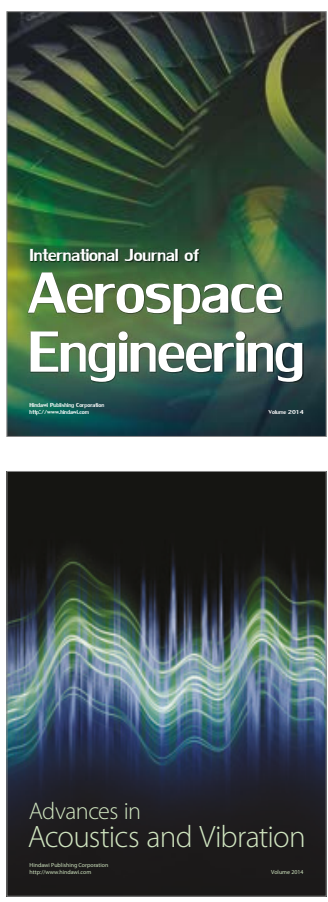

Sensor Networks 